\title{
The Magnitude of Diabetes Mellitus in Adult Hypertensive Patients in Northeast Ethiopia
}

This article was published in the following Dove Press journal:

Diabetes, Metabolic Syndrome and Obesity: Targets and Therapy

\author{
Mekuriaw Wuhib Shumye' \\ Belachew Tegegne' \\ Sewunet Ademe $\mathbb{D}^{\prime}$ \\ Moges Workneh' \\ Million Abera ${ }^{2}$ \\ Gugsa Nemera $\mathbb{1}^{2}$ \\ Fikadu Balcha $\mathbb{D}^{2}$ \\ 'School of Nursing and Midwifery, \\ College of Medicine and Health Science, \\ Wollo University, Dessie, Ethiopia; \\ ${ }^{2}$ School of Nursing, Faculty of Health \\ Sciences, Institute of Health, Jimma \\ University, Jimma, Ethiopia
}

\begin{abstract}
Background: Hypertension and diabetes mellitus are the most common comorbid noncommunicable chronic diseases that threaten human beings worldwide. Hypertension is associated with an increased risk of diabetes mellitus and vis-a-vis. However, there is limited information on the magnitude of diabetes mellitus in hypertensive patients in sub-Saharan countries. Hence, this study assessed the magnitude of diabetes mellitus and its associated factors among adult hypertensive patients attending a hypertension clinic in Northeast Ethiopia.
\end{abstract}

Methods: Institution-based cross-sectional study conducted on 407 participants from April to June 2019. The participants were included in the study using systematic random sampling. Data were collected using the WHO STEPwise method. We run descriptive statistics to determine the magnitude of diabetes mellitus in hypertensive patients and logistic regression to identify factors associated with diabetes, and statistically significant associations were declared at a P-value of less than 0.05 .

Results: The magnitude of diabetes mellitus among hypertensive patients was $29.1 \%$, of whom $24 \%$ were newly diagnosed. Respondents with a family history of diabetes mellitus (AOR: 4.6, CI: 2.2, 9.48), increased waist-to-height ratio (AOR: 21.5, CI: 5.62,43.67), increased waist circumference (AOR: $3.2, \mathrm{CI}: 1.58,6.53$ ) and primary school educational status (AOR: 3.2, CI: 1.41, 7.25) were more likely to have diabetes. Similarly, respondents with longer hypertension duration (AOR: 4.09, CI: 1.22, 13.64), past daily smoking history (AOR: 10.46, CI: 1.59,6.8), increased diastolic blood pressure (AOR: 4.15, CI: 1.51, 11.37), and increased waist circumference (AOR: 7.5, CI: 4.47,14.95) were more likely to be diagnosed newly for diabetes.

Conclusion: Our study indicated around one-third of hypertensive patients had diabetes. Family history of diabetes mellitus, primary educational status and increased waist-to-height ratio and waist circumference were significant predictors of diabetes among hypertensive patients. The finding suggests the need for regular diabetic screening among hypertensive patients.

Keywords: magnitude, hypertension, diabetes mellitus, Ethiopia

\section{Background}

Hypertension (HTN) and diabetes mellitus (DM) are among the non-communicable chronic diseases (NCD) that threaten human beings throughout the entire world. ${ }^{1}$ According to the American College of Cardiology, hypertension refers to a persistent elevation of systolic blood pressure at or above $130 \mathrm{mmHg}$ and/or diastolic blood pressure at or above $80 \mathrm{mmHg}^{2}$ Diabetes mellitus refers to a metabolic disorder of carbohydrate, protein, and fat, which is associated with hyperglycemia and a broad range of clinical presentations. Type two DM is the 
most common type of diabetes, which can be prevented or delayed with lifestyle modifications, otherwise expressed as low glucose control or elevated plasma glucose. ${ }^{3}$

The 2019 international diabetes federation (IDF) report showed that the prevalence of diabetes was $8.3 \%$ globally, 4.7\% in Africa and 5.2\% in Ethiopia. Africa is the continent with a high burden of diabetes, where over 16 million adults 20 and 70 years lived with diabetes in the continent in 2017. This figure is projected to increase by $156 \%$, reaching over 41 million in 2045. On the other hand, Ethiopia is one of the most populous countries in Africa and is among the top five countries with the highest numbers of people with diabetes. ${ }^{4,5}$ Over two-third of diabetic cases in low-income countries like Ethiopia are undiagnosed, living without knowing that they have diabetes. ${ }^{5}$

Diabetes is the most common reported comorbid condition to hypertension. On the other hand, increased blood pressure is a risk factor for diabetes. ${ }^{6-8}$ Office and masked hypertension are associated with long-term blood glucose abnormalities and an increased risk of developing diabetes. ${ }^{9}$ Studies reported from Asia and Africa showed that diabetes prevalence among hypertensive patients ranges from $9.8 \%$ to $24 \% .^{10-14}$ The prevalence of newly diagnosed diabetes among hypertensive patients varies by region. For example, it accounts for $3.4 \%$ to $20.8 \%{ }^{15-17}$ in China and $6.8 \%$ to $22.1 \%$ in Africa. ${ }^{13,14,18}$

If not well managed, the comorbidity of hypertension and T2DM is complex and associated with a high chance of complications. ${ }^{19}$ Diabetes-related microvascular complications are higher in T2DM patients with hypertension than those without hypertension. ${ }^{20}$ Thus, WHO recommends that hypertensive patients undergo diabetes screening with varying frequency based on their risk profile. ${ }^{21}$

The driving forces behind the two disease co-morbidity are family history, unhealthy eating, reduced physical activity, smoking, sedentary behavior, non-current smoking, and current alcohol drinking. ${ }^{11,12,14-17,22,23}$ Overweight, obesity, elevated blood pressure, higher waists to height ratio above 0.5 have a significant association with $\mathrm{DM},{ }^{6,8,11,14,16,17,24}$ whereas controlled blood pressure below $140 / 90 \mathrm{mmHg}$ is protective against diabetes. ${ }^{11,13,15,25}$ A combination of many factors like limited access to healthcare services, inadequate training among healthcare professionals, and lack of awareness of diabetes symptoms contributes to the highest proportion of undiagnosed diabetes in low-income countries. ${ }^{5}$

In 2019, half the 463 million adults living with diabetes were unaware that they had diabetes. This could also be related to the alarmingly rising diabetes in Africa including Ethiopia, where over two-thirds of them do not know that they have diabetes. On the other hand, an upsurge in hypertension might lead to an upsurge in T1DM and related risk factors. In public hospitals of Ethiopia, diabetes screening among hypertensive patients has not been standard of care for hypertensive patients on follow-up in the hypertension clinics. To our knowledge, in Ethiopia, there has been limited evidence on the magnitude of diabetes among hypertensive patients. Therefore, this study aimed to determine the magnitude of diabetes and its associated risk factors among hypertensive patients attending Dessie comprehensive specialized hospital, Northeast Ethiopia.

\section{Methods and Materials Study Design and Setting}

An institution-based cross-sectional study was conducted from April to June 2019 in Dessie comprehensive and specialized hospital (DCSH), North-East Ethiopia. The hospital serves around 7 million people with 240 beds capacity. The outpatient service hypertension clinic is one of the hospital's outpatient department providing follow-up services for 934 registered patients.

\section{Study Participants}

Hypertensive patients aged 18 years and above who were on follow-up in the DCSH hypertension unit during the study period were included in the study. 1) Pregnant hypertensive women, 2) Patients who developed hypertension secondary to diabetes mellitus or who were diagnosed at the same time for both diseases, and 3) Hypertensive patients unable to respond due to severe illness were excluded from the study. Co-morbid patients for hypertension and diabetes were asked which disease was diagnosed first for inclusion and exclusion criteria before including in the study. Systematic random sampling was applied to select 423 study participants out of 934 registered patients on regular follow-up at the DCSH hypertension clinic, and the first patient on the list was identified using a lottery method (Figure 1).

\section{Data Collection}

A structured questionnaire adapted from the WHO STEPwise approach translated to Amharic by Jimma University Gilgel Gibe research project was used. ${ }^{26}$ The questionnaire consists of 5 items, and information about 


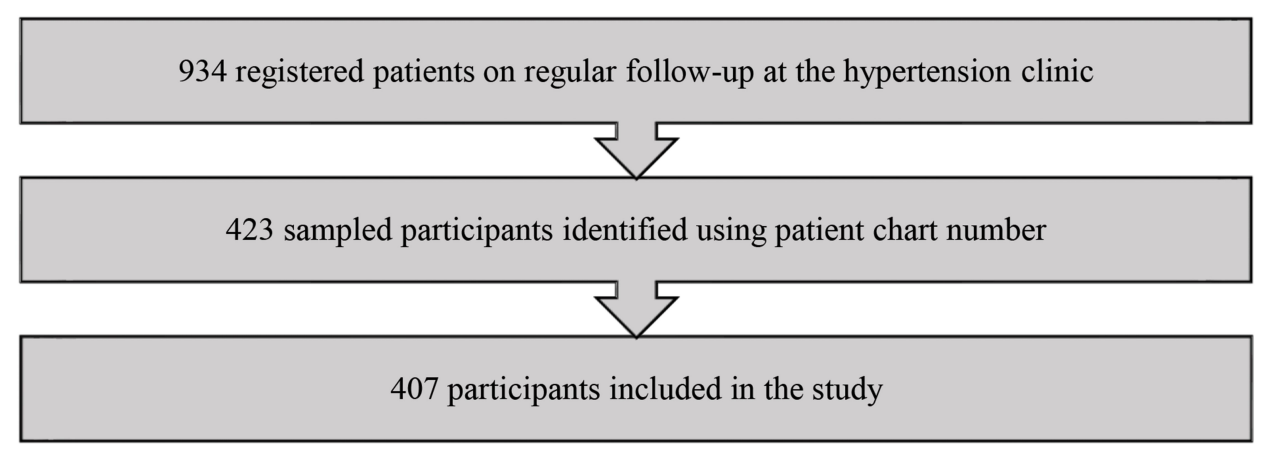

Figure I Flow diagram of participant recruitment.

patient height, weight, waist circumference, blood pressure, fasting blood sugar level, and heart rate. The data were collected by two-degree level nurses and two laboratory technologists trained for one day on the objective and relevance of the study, confidentiality and right of participants and correct methods of anthropometric measurements. To reduce social desirability bias, nurses working in the hypertension clinic were not involved in data collection.

Blood pressure (BP) was measured with an Omron Hem-7121digital sphygmomanometer with the BP machine cuff placed at the mid-arm. Three intermittent blood pressure readings were recorded with five minutes rest between each measurement and the average is used for this study similar to other international surveys.

Heart rate reading was taken from a digital BP measuring instrument. Height $(\mathrm{cm})$ was measured using the vertical measuring board (stadiometer). For height measurement, each participant was asked to remove his/her shoes, cap/ hat, and stand on both feet on a flat surface/board with heels together in an erect position and the value was read at the exact point and recorded to the nearest $0.5 \mathrm{~cm}$.

Weight $(\mathrm{kg})$ was measured using a standardized weight scale. The participant was asked to remove their footwear, take off coat or jacket and heavy clothing while standing in the center of the weighing scale with body weight evenly distributed between both feet.

Waist circumference (WC) in $\mathrm{cm}$ was determined by using a non-extensible/non-stretchable tape measure that was placed around the midway between the last rib and the superior iliac crest, and the recording was taken at the point of normal expiration to the nearest $0.5 \mathrm{~cm}$. Venous blood was drawn after 8 or more hours of fasting. Then blood glucose was determined by using the chemistry machine model Dirrul CST-240. For those first blood sugar labels $>125 \mathrm{mg} / \mathrm{dl}$, the test was repeated on the next day again in a fasting state by using a similar machine and test procedure.

Body-mass index (BMI) was calculated as weight $(\mathrm{kg})$ divided by height (in meters) squared. Waist to height ratio (WHR) was calculated as waist circumference (cm) divided by height $(\mathrm{cm})$. The questionnaire and physical measurement took 15-20 minutes on average to complete.

Besides, we have also collected information about socio-demographic characteristics (age, educational status, income, marital status, employment, sex and residence), behavioral measurements (tobacco use, alcohol consumption, physical activity label, diet, and sedentary behavior), biological variables (heart rate, diastolic blood pressure, systolic blood pressure, BMI, waist circumference, and waist to height ratio), family history of diabetes and hypertension-related variables (duration of hypertension, use of traditional healers, use of prescribed medication, or advice for hypertension). The dependent variables of this study were the magnitude of diabetes mellitus. Similarly, the independent variables were sociodemographic characteristics, behavioral measurements, biological variables, family-related variables, and hypertension-related variables.

To ensure data quality, a pre-test was conducted on $5 \%$ of the total sample size in another hospital, Boru hospital, before the actual data collection period. Based on the pre-test skip errors and few locally less understood wordings were modified. Moreover, the average time required for the interview and anthropometric measurements was determined.

\section{Measurements}

Our primary outcome variable was the fasting plasma glues (FPG) level. The response variables include sociodemographic characteristics (age, educational status, 
income, marital status, employment, sex and residence), behavioral outcomes (tobacco use, alcohol consumption, physical activity and diet), biological (heart rate, diastolic BP, systolic BP, BMI, waist circumference and waist to height ratio), family history of diabetes and hypertensionrelated variables (duration and use of traditional healers, prescribed medication or advice).

A participant can be considered pre-diabetic if his or her fasting plasma glucose (FPG) is $100-125 \mathrm{mg} / \mathrm{dL} ;{ }^{27}$ newly diagnosed for diabetes mellitus, when he or she was not diagnosed for diabetes before this study and if two fasting plasma glucose (FPG) measurement with the same machine is $\geq 126 \mathrm{mg} / \mathrm{dL} \quad(\geq 7.0 \mathrm{mmol} / 1) ;^{4,27}$ and Overweight when his or her BMI is between 25.0 and $29.9 \mathrm{~kg} / \mathrm{m}^{2}$, otherwise obese if his her BMI is greater than or equal to $30.0 \mathrm{~kg} / \mathrm{m}^{2}$ or more. ${ }^{27}$ A waist circumference $>94 \mathrm{~cm}$ for male and $>80 \mathrm{~cm}$ for a female is considered as increased risk and a waist circumference $>102 \mathrm{~cm}$ for male and $>88 \mathrm{~cm}$ for a female is considered as substantially increased risk for cardio-metabolic diseases. $^{27}$ Optimal waist to height ratio (reduced risk of cardiometabolic diseases) was defined as less than 0.5 and above normal if it is above $0.5 .^{24}$

A patient is considered a tobacco user if he or she daily uses smoked or smokeless tobacco in the form of cigarettes, cigars, pipes, snuff, and other local tobacco products. ${ }^{28}$ A patient is considered as highly physically active when his or her metabolic equivalent (MET) is greater than or equal to 3000; physically active when his or her MET is in the range of equal to 600-2999; physically inactive when his or her MET is less than $600 .^{29}$ A patient consumes insufficient fruits and vegetables if he or she consumes less than the recommended five servings of fruits or vegetables daily. ${ }^{28}$

\section{Data Analysis}

Data were coded and entered into the computer using an Epi Data entry client 4.2.1 and exported to SPSS version 23 for analysis. Variables observed in the bivariate analysis at P-value 0.25 and less were candidates for multivariable logistic regression analysis. Logistic regression backward method was run to explore the level of association. The strength of statistical association was reported as adjusted odds ratios with $95 \%$ confidence intervals.

\section{Ethical Consideration}

This study was conducted in accordance with the ethical standards of the institutional and/or national research committee and with the 1964 Helsinki declaration and its later amendments or comparable ethical standards.

Before the commencement of data collection, ethical approval was secured from the institutional review board of Jimma University Institute of Health (JUIH). During data collection written informed consent was obtained from each of the study participants after explaining the study purpose, procedure, and duration of the study. Written informed consent taken from study participants was approved by the institutional review board of Jimma University Institute of Health. Participants were also informed that they have a full right to withdraw from the study without affecting their routine care. The blood sample taken for FPG was discarded immediately after blood sugar determination per the hospital sample discarding protocol. Based on the result, each patient was told their diabetic status. Those who were newly diagnosed and pre-diabetic were counseled on lifestyle modification and linked to the hospital chronic diabetic follow-up unit.

\section{Results}

\section{Socio-Demographic Characteristics}

Four hundred seven (407) adult hypertensive patients were included in this study with a response rate of $96.2 \%$. The result includes socio-demographic characteristics, behavioral measurements, the magnitude of diabetes and factors associated with diabetes. Out of 407 participants, around half $(50.6 \%)$ of them were males. The mean $( \pm \mathrm{SD})$ age of the participants was 60.4 $( \pm 12.1)$ years, with around one-third $(33.4 \%)$ of them above the age of 65 years, and over half $(55.8 \%)$ of them had no formal education. Most (71\%) of them married, $84.5 \%$ of them were urban residents, and $43.5 \%$ of them had a monthly income of less than 1000 ETB [Ethiopian Birr] (Table 1).

\section{Behavioral Measurements}

Around $4 \%$ of the study participants had a history of smoking. Around $9 \%$ of the study participants had a history of alcohol intake for at last a year, among which $45.7 \%$ of them consumed alcohol in the last month. Of all the participants, 57.1\% were physically inactive, $62.9 \%$ used semi-solid oil at room temperature, and almost all of them (99.7\%) had less than the recommended amount of fruit/vegetable intake (Table 2). 
Table I Socio-Demographic Characteristics of the Study Participants $(n=407)$

\begin{tabular}{|c|c|c|c|}
\hline \multicolumn{2}{|l|}{ Variables } & \multirow{2}{*}{$\begin{array}{l}\text { Frequency } \\
206 \\
201\end{array}$} & \multirow{2}{*}{$\begin{array}{l}\text { Percent } \\
50.6 \\
49.4\end{array}$} \\
\hline Gender & $\begin{array}{l}\text { Male } \\
\text { Female }\end{array}$ & & \\
\hline Age & $\begin{array}{l}18-40 \\
4 I-65 \\
\text { Above } 65\end{array}$ & $\begin{array}{l}32 \\
239 \\
136\end{array}$ & $\begin{array}{l}7.9 \\
58.7 \\
33.4\end{array}$ \\
\hline $\begin{array}{l}\text { Educational } \\
\text { status }\end{array}$ & $\begin{array}{l}\text { No formal schooling } \\
\text { Primary school } \\
\text { completed } \\
\text { Secondary school } \\
\text { completed } \\
\text { College and above }\end{array}$ & $\begin{array}{l}227 \\
38 \\
45 \\
97\end{array}$ & $\begin{array}{l}55.8 \\
9.3 \\
11.1 \\
23.8\end{array}$ \\
\hline Residence & $\begin{array}{l}\text { Urban } \\
\text { Rural }\end{array}$ & $\begin{array}{l}344 \\
63\end{array}$ & $\begin{array}{l}84.5 \\
15.5\end{array}$ \\
\hline Marital status & $\begin{array}{l}\text { Not married } \\
\text { Married } \\
\text { Divorced } \\
\text { Widowed }\end{array}$ & $\begin{array}{l}8 \\
289 \\
30 \\
80\end{array}$ & $\begin{array}{l}2.0 \\
71.0 \\
7.4 \\
19.7\end{array}$ \\
\hline Occupation & $\begin{array}{l}\text { Farmer } \\
\text { Government employed } \\
\text { Privately employed } \\
\text { Merchant } \\
\text { Housewife } \\
\text { Retired } \\
\text { Unemployed }\end{array}$ & $\begin{array}{l}71 \\
70 \\
15 \\
19 \\
155 \\
57 \\
20\end{array}$ & $\begin{array}{l}17.4 \\
17.2 \\
3.7 \\
4.7 \\
38.1 \\
14.0 \\
4.9\end{array}$ \\
\hline $\begin{array}{l}\text { Monthly } \\
\text { income }\end{array}$ & $\begin{array}{l}\text { Less than I000 Birr } \\
\text { I000-5000 Birr } \\
\text { Above } 5000 \text { Birr }\end{array}$ & $\begin{array}{l}177 \\
192 \\
38\end{array}$ & $\begin{array}{l}43.5 \\
47.2 \\
9.3\end{array}$ \\
\hline
\end{tabular}

Abbreviation: DCSH, Dessie Comprehensive Specialized Hospital.

\section{Magnitude of Diabetes Mellitus and Associated Factors}

The magnitude of diabetes mellitus among DCSH hypertensive patients was $29 \%$, of which $23.5 \%$ of them were newly diagnosed. Out of all the participants, the proportion of patients diagnosed newly for diabetes was $6.9 \%$. On the other hand, $21.4 \%$ (87) of the study participants were prediabetics (Figure 2).

Our multiple logistic regression model showed educational status, past daily smoking history, family history of diabetes; hypertension duration, diastolic blood pressure, and waist circumference were significantly associated with diabetes mellitus among hypertensive patients. The odds of developing diabetes in patients with hypertension patients was higher 4.6 (AOR 4.6, 95\% CI 2.2, 9.48) for
Table 2 Behavioral Characteristics of the Study Participants ( $\mathrm{n}=407$ )

\begin{tabular}{|c|c|c|c|}
\hline \multicolumn{2}{|l|}{ Variables } & \multirow{2}{*}{$\begin{array}{l}\text { Frequency } \\
4 \\
403\end{array}$} & \multirow{2}{*}{$\begin{array}{l}\text { Percent } \\
1.0 \\
99.0\end{array}$} \\
\hline Current smokers & $\begin{array}{l}\text { Yes } \\
\text { No }\end{array}$ & & \\
\hline Past smokers & $\begin{array}{l}\text { Yes } \\
\text { No }\end{array}$ & $\begin{array}{l}16 \\
391\end{array}$ & $\begin{array}{l}3.9 \\
96.1\end{array}$ \\
\hline $\begin{array}{l}\text { Last year alcohol } \\
\text { use }\end{array}$ & $\begin{array}{l}\text { Yes } \\
\text { No }\end{array}$ & $\begin{array}{l}35 \\
372\end{array}$ & $\begin{array}{l}8.5 \\
91.5\end{array}$ \\
\hline $\begin{array}{l}\text { Last month alcohol } \\
\text { use }(n=35)\end{array}$ & $\begin{array}{l}\text { Yes } \\
\text { No }\end{array}$ & $\begin{array}{l}16 \\
19\end{array}$ & $\begin{array}{l}45.7 \\
54.3\end{array}$ \\
\hline $\begin{array}{l}\text { Physical activity } \\
\text { label }\end{array}$ & $\begin{array}{l}\text { Physically inactive } \\
\text { Physically } \\
\text { moderately active } \\
\text { Physically highly } \\
\text { active }\end{array}$ & $\begin{array}{l}232 \\
155 \\
20\end{array}$ & $\begin{array}{l}57.0 \\
38.1 \\
4.9\end{array}$ \\
\hline Fruit/vegetable use & $\begin{array}{l}\text { Adequate } \\
\text { Inadequate }\end{array}$ & $\begin{array}{l}1 \\
406\end{array}$ & $\begin{array}{l}0.2 \\
99.8\end{array}$ \\
\hline Oil type used & $\begin{array}{l}\text { Semi-solid at room } \\
\text { temperature } \\
\text { Liquid at room } \\
\text { temperature } \\
\text { Non in particular }\end{array}$ & $\begin{array}{l}256 \\
141 \\
10\end{array}$ & $\begin{array}{l}62.9 \\
34.6 \\
2.45\end{array}$ \\
\hline
\end{tabular}

Abbreviation: DCSH, Dessie Comprehensive Specialized Hospital.

those having a family history of diabetes. On the other hand, participants with a waist-to-hip ratio above 0.5 were around 22 times (AOR: 21.55, 95\% CI: 5.62, 43.67) more likely to develop diabetes than those with less than 0.5 . Similarly, male hypertensive patients with a waist circumference above $102 \mathrm{~cm}$ and female participants with a waist circumference above $88 \mathrm{~cm}$ were 3 times more likely (AOR: $3.2,95 \%$ CI: $1.58,6.53$ ) to develop diabetes compared to their counterparts (Table 3 ).

Regarding, factors associated with newly diagnosed diabetes, participants with past daily smoking history were ten times more likely (AOR: 10.46, 95\% CI: 5.1, 16.8) to be diagnosed newly for diabetes compared to those with no history of daily smoking. Similarly, the odds of being diagnosed newly for diabetes was 4 times higher (AOR: 4.09, 95\% CI: 1.22, 13.64) among participants who lived with hypertension for 5 to 10 years compared to those who lived with hypertension for less than five years. Participants with a diastolic blood pressure of $90 \mathrm{mmHg}$ and above (AOR: 4.15, 95\% CI: 1.51, 11.37) were more likely to be diagnosed newly for diabetes compared to those with less than $90 \mathrm{mmHg}$. Similarly, 


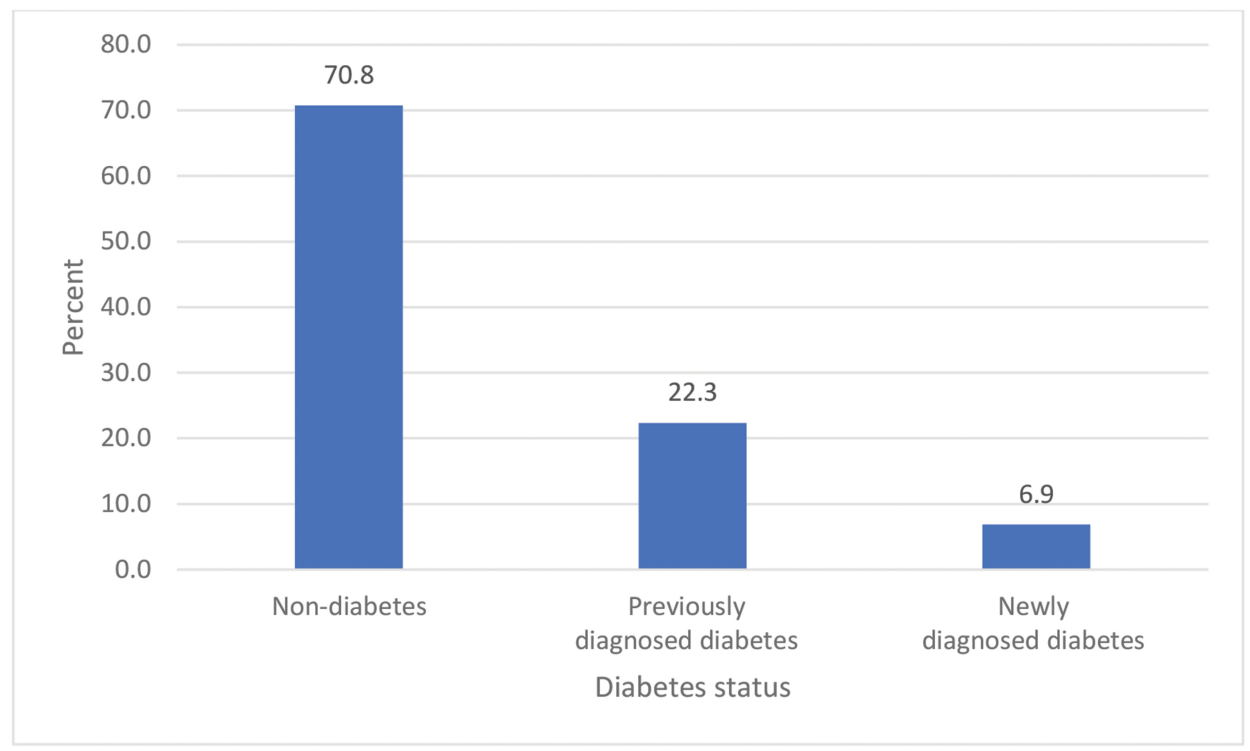

Figure 2 Magnitude of diabetes mellitus among hypertensive patients.

waist circumference above $102 \mathrm{~cm}$ for males and above $88 \mathrm{~cm}$ for females (AOR: 13.7, 95\% CI: 4.47, 14.95) was also associated with increased risk of newly diagnosed diabetes (Table 3).

\section{Discussion}

The findings of this study showed the magnitude of diabetes mellitus among hypertensive patients was high (29\%), which indicates a significant number of hypertensive patients are at the greatest risk of developing unnoticed complications. This finding is comparable with the magnitude reported $(32 \%)$ by the study conducted in China. ${ }^{16}$ However, our finding was greater than the prevalence of diabetes reported by the study conducted among newly diagnosed hypertensive patients in Cameron $7.7 \%{ }^{13}$ Algeria $21.8 \%{ }^{30}$ and China $24.3 \% .^{15}$ The possible reason for the greater prevalence in our study would be due to the fact that the study subjects in Cameroon study participants were newly diagnosed hypertensive patients. In addition, the mean age of the study participants of the study conducted in Cameroon was less than $(50.8 \pm 11)$ our study participants' mean age of (60.39 \pm 12 ) which be associated with higher diabetes prevalence. ${ }^{13}$ On the other hand, our study showed that the prevalence of previously diagnosed diabetes among hypertensive patients $(22.35 \%)$ was slightly higher than the finding of the studies reported from China, which ranged from $3.4 \%$ to $15.86 \% .{ }^{15-17}$ This may be due to a lack of engagement in the prevention of diabetes and less health-seeking behavior among hypertensive patients in Ethiopia that could lead to a higher chance of developing diabetes. ${ }^{31}$

The current study showed the magnitude of newly diagnosed diabetes mellitus among adult hypertensive patients was $6.9 \%$, which is in line with the finding of a study reported from Cameroon (6.8\%) and China $(8.0 \%) .{ }^{13,15}$ However, it is less than the finding of the studies conducted in the US, Minnesota that reported $19.6 \%,{ }^{32}$ Kenya $14.0 \%,{ }^{11}$ and China $9.8 \%$ and $20.8 \%{ }^{16,17}$ These discrepancies might be related to using different glucose measurement methods like glycated hemoglobin (HbA1C), fasting plasma glucose, or oral glucose tolerance test (OGTT) to determine diabetes status. The other reason could be the significant socioeconomic differences of Ethiopia, China, and the US study participants.

The current study findings showed the magnitude of diabetic mellitus among hypertensive patients varies by educational status, past daily smoking history, family history of diabetes, duration of hypertension, diastolic blood pressure, and increased waist circumference. Those hypertensive patients at odds of having these variables are at the most significant risk of diabetes mellitus. For example, those who had a family history of diabetes mellitus have an increased chance of developing diabetes. This is supported by other studies conducted in Ethiopia, Kenya, Uganda, China, and Japan. ${ }^{11,14-17,22,23}$ This could be related to the overlapping genetic predisposition linked to 
Table 3 Univarate and Multivariate Logistic Regression Analyses Showing Factors Associated with Diabetes Mellitus Among Hypertensive Patients

\begin{tabular}{|c|c|c|c|}
\hline \multicolumn{2}{|l|}{ Variables } & \multirow{2}{*}{$\begin{array}{l}\text { All Cases of DM AOR (CI) } \\
\text { I } \\
3.2(1.41,7.25)^{*} \\
0.93(0.39,2.23) \\
1.658(0.88,3.1 \mathrm{I})\end{array}$} & \multirow{2}{*}{$\begin{array}{l}\text { Newly Diagnosed DM AOR (Cl) } \\
\mathrm{I} \\
3.4(0.98,11.8) \\
1.19(0.24,5.24) \\
3.64(1.49,8.85)\end{array}$} \\
\hline Education & $\begin{array}{l}\text { No formal schooling } \\
\text { Primary school completed } \\
\text { Secondary school completed } \\
\text { College and above }\end{array}$ & & \\
\hline Past daily smokers & $\begin{array}{l}\text { No } \\
\text { Yes }\end{array}$ & $\begin{array}{l}\text { I } \\
4.3(1.53,12.05)\end{array}$ & $\begin{array}{l}\text { I } \\
10.46(1.59,6.8)^{*}\end{array}$ \\
\hline DM family history & $\begin{array}{l}\text { No } \\
\text { Yes }\end{array}$ & $\begin{array}{l}\text { I } \\
4.6(2.2,9.48)^{* *}\end{array}$ & $\begin{array}{l}\text { I } \\
3.31(1.25,9.05)\end{array}$ \\
\hline WHR & $\begin{array}{l}0.5 \text { and below } \\
\text { Above } 0.5\end{array}$ & $\begin{array}{l}\text { I } \\
21.5(5.62,43.67)^{* * *}\end{array}$ & Not candidate at binary \\
\hline HTN duration & $\begin{array}{l}\text { Below } 5 \text { years } \\
5-10 \text { year } \\
\text { Above } 10 \text { years }\end{array}$ & $\begin{array}{l}\text { I } \\
2.07(I .13,3.78) \\
2.5(1.39,4.52)\end{array}$ & $\begin{array}{l}\text { I } \\
4.09(1.22,13.64)^{*} \\
2.082(0.56,7.75)\end{array}$ \\
\hline Diastolic BP & $\begin{array}{l}\text { Below } 90 \mathrm{mmHg} \\
90 \mathrm{mmHg} \text { and above }\end{array}$ & I & $\begin{array}{l}\text { I } \\
4.15(1.51,11.37)^{* *}\end{array}$ \\
\hline Waist circumference & $\begin{array}{l}102 \text { and below for male and } 88 \text { and below for female } \\
\text { Above } 102 \text { for male and above } 88 \text { for female }\end{array}$ & $\begin{array}{l}\text { I } \\
3.2(1.58,6.53) * *\end{array}$ & $\begin{array}{l}\text { I } \\
7.5(4.47,14.95)^{* *}\end{array}$ \\
\hline
\end{tabular}

Notes: *P value $<0.05$; **P value $<0.0$ I; ***P value $<0.00$ I; I, reference; overall statistics, 0.76 .

Abbreviations: AOR, adjusted odds ratio; BMI, body mass index; BP, blood pressure; Cl, confidence interval; DM, diabetes mellitus; ETB, Ethiopian birr; HTN, hypertension; WHR, waist-to-height ratio.

both hypertension and diabetes. On the other hand, the current study revealed that history of previous daily smoking was significantly associated with an increased risk of new diabetes mellitus diagnosis. This finding is supported by findings of studies conducted in China and Ethiopia. ${ }^{17,23}$ Smoking has been reported as an independent risk factor of diabetes mellitus related to insulin resistance, low production of insulin and increased abdominal obesity. ${ }^{33,34}$ The probability of developing newly diagnosed diabetes mellitus among hypertension patients was significantly associated with hypertension duration. The possible reason for this would be longer duration hypertension can lead to insulin resistance. Our study showed that diastolic blood pressure of $90 \mathrm{mmHg}$ and above was significantly associated with newly diagnosed diabetes mellitus. This finding is in line with the finding study conducted in the United Kingdom. ${ }^{6,8}$ Uncontrolled high blood pressure over a longer period is associated with an increased risk of diabetes-related complications and other cardiovascular diseases. ${ }^{35}$

Increased waist circumference was also significantly associated with the risk of developing diabetes mellitus. This result was in line with the findings of studies conducted in China. ${ }^{16,17}$ Waist circumference is a better indicator of metabolic syndrome risk than body mass index and waist to hip circumference ratio. ${ }^{12,36}$ Similarly, those who had a waist-to-height ratio above 0.5 were more likely to develop diabetes compared to those who had a waist-to-height ratio of 0.5 and below. This finding is supported by the finding of the study conducted in China. ${ }^{24}$ In obese individuals, adipose tissue may release an increased amount of non-esterified fatty acids, glycerol, hormones, pro-inflammatory cytokines and other factors that are involved in the development of insulin resistance that increases the risk of diabetes. ${ }^{37}$

Overall, our study showed that 1 in 3 of hypertensive patients had diabetes. Having family histories of diabetes, a history of daily smoking, increased waist-to-height ratio and waist circumference, longer hypertension duration and increased diastolic blood pressure were significantly associated with an increased chance of developing diabetes mellitus. We, therefore, recommend screening of hypertensive patients for diabetes as part of routine hypertensive care.

The interpretation of the findings of our study can be affected by several limitations. The study finding cannot 
be generalized to the general population as this was a hospital-based cross-sectional study. Obesity parameters such as WC and BMI cutoff sizes may be different for low-income countries like Ethiopia. Moreover, the fasting blood glucose test that we used for diagnoses of diabetes is weak compared to glycated hemoglobin in identifying diabetes mellitus.

\section{Abbreviations}

BMI, body mass index; CVD, cardiovascular disease; CI, confidence interval; DBP, diastolic blood pressure; DM, diabetes mellitus; DCSH, Dessie Comprehensive Specialized Hospital; FPG, fasting plasma glucose; HPN, hypertension; IDF, International Diabetes Federation; IFG, impaired fasting glucose; IGT, impaired glucose tolerance; NCD, noncommunicable disease; PI, principal investigator; STEPS, STEPwise Approach to Surveillance; SBP, systolic blood pressure; WC, waist circumference; WHO, World Health Organization.

\section{Data Sharing Statement}

The data can be accessed from the corresponding author on request.

\section{Acknowledgment}

We would like to thank Mr. Fasil Tessema (BSc, MSc, associate prof) for his great contribution by giving an Amharic version of data collection tools. Our appreciation goes to health workers at DCSH, who gave us basic support to do this research. We would like to thank my data collectors and lastly, we would like to thank our study participants for their participation in the stud.

\section{Author Contributions}

All authors made a significant contribution to the work reported, whether that is in the conception, study design, execution, acquisition of data, analysis and interpretation, or in all these areas; took part in drafting, revising or critically reviewing the article; gave final approval of the version to be published; have agreed on the journal to which the article has been submitted; and agree to be accountable for all aspects of the work.

\section{Funding}

The study was funded by Jimma University. The funders had no role in study design, data collection and analysis, decision to publish, or preparation of the manuscript.

\section{Disclosure}

The authors declare that they have no conflicts of interest for this work.

\section{References}

1. World Health Organization. Global action plan for the prevention and control of noncommunicable diseases 2013-2020. World Health Organization; 2013. Available from: https://apps.who.int/iris/handle/ 10665/94384. Accessed January 23, 2020.

2. Whelton PK, Carey RM, Aronow WS, et al. 2017 ACC/AHA/AAPA/ $\mathrm{AB} / \mathrm{ACPM} / \mathrm{AGS} / \mathrm{APhA} / \mathrm{ASH} / \mathrm{ASPC} / \mathrm{NMA} / \mathrm{PCNA}$ Guideline for the prevention, detection, evaluation, and management of high blood pressure in adults: a report of the American College of Cardiology/ American Heart Association Task Force on Clinical Practice Guidelines. J Am Coll Cardiol. 2018;71(19):e127-e248. doi:10.10 16/j.jacc.2017.11.006

3. Seino Y. The committee of the Japan diabetes society on the diagnostic criteria of diabetes mellitus. Diabetol Int. 2010;1:2-20. doi:10.1007/s13340-010-0006-7

4. IDF. Diabetes Atlas - 8th Edition. International Diabetes Federation; 2017. Available from: https://www.diabetesatlas.org/upload/resources/ previous/files/8/IDF_DA_8e-EN-final.pdf. Accessed December 28, 2020.

5. IDF. Diabetes atlas ninth edition. International Diabetes Federation; 2019. Available from: https://www.diabetesatlas.org/upload/ resources/material/20200302_133351_IDFATLAS9e-final-web.pdf. Accessed December 28, 2020.

6. Sepehri A, Palazón-Bru A, Gil-Guillén VF, et al. Diabetes screening: a pending issue in hypertense/obese patients. PeerJ. 2015;3:e914. doi:10.7717/peerj.914

7. Movahed M-R, Sattur S, Hashemzadeh M. Independent association between type 2 diabetes mellitus and hypertension over a period of 10 years in a large inpatient population. Clin Exp Hypertens. 2010;32 (3):198-201. doi:10.3109/10641960903254539

8. Emdin CA, Anderson SG, Woodward M, Rahimi K. Usual blood pressure and risk of new-onset diabetes: evidence from 4.1 million adults and a meta-analysis of prospective studies. $\mathrm{J} \mathrm{Am} \mathrm{Coll} \mathrm{Cardiol}$. 2015;66(14):1552-1562. doi:10.1016/j.jacc.2015.07.059

9. Mancia G, Bombelli M, Facchetti R, et al. Increased long-term risk of new-onset diabetes mellitus in white-coat and masked hypertension. J Hypertens. 2009;27(8):1672-1678. doi:10.1097/HJH.0b013e32832 be 5 f9

10. Dokunmu TM, Yakubu OF, Adebayo AH, Olasehinde GI, Chinedu SN. Cardiovascular risk factors in a suburban community in Nigeria. Int J Hypertens. 2018;2018:1-6. doi:10.1155/2018/6898527

11. Meme N, Amwayi S, Nganga Z, Buregyeya E. Prevalence of undiagnosed diabetes and pre-diabetes among hypertensive patients attending Kiambu district Hospital, Kenya: a cross-sectional study. Pan Afr Med J. 2015;22(1). doi:10.11604/pamj.2015.22.286.7395

12. Echouffo-Tcheugui JB, Dzudie A, Epacka ME, et al. Prevalence and determinants of undiagnosed diabetes in an urban sub-Saharan African population. Prim Care Diabetes. 2012;6(3):229-234. doi:10. 1016/j.pcd.2012.05.002

13. Kamdem F, Lemogoum D, Doualla MS, et al. Glucose homeostasis abnormalities among Cameroon patients with newly diagnosed hypertension. J Clin Hypertens. 2017;19(5):519-523. doi:10.1111/ jch.12959

14. Mutebi E, Nakwagala F, Nambuya A, Otim M. Undiagnosed diabetes mellitus and impaired glucose tolerance among hypertensive patients in Mulago Hospital, Kampala, Uganda. Afr J Diabetes Med. 2012;20.

15. Liu J, Zhao D, Liu J, Qi Y, Sun J, Wang W. Prevalence of diabetes mellitus in outpatients with essential hypertension in China: a cross-sectional study. BMJ Open. 2013;3(11):e003798. doi:10.1136/ bmjopen-2013-003798 
16. Huang X-B, Tang W-W, Liu Y, et al. Prevalence of diabetes and unrecognized diabetes in hypertensive patients aged 40 to 79 years in southwest China. PLoS One. 2017;12(2):e0170250. doi:10.1371/journal.pone. 0170250

17. Qin X, Li J, Zhang Y, et al. Prevalence and associated factors of diabetes and impaired fasting glucose in Chinese hypertensive adults aged 45 to 75 years. PLoS One. 2012;7(8):e42538. doi:10.1371/ journal.pone. 0042538

18. Machingura PI, Murambiwah R. Prevalence of undiagnosed diabetes mellitus amongst hypertensive patients attending an outpatient clinic in Harare, Zimbabwe. Prevalence. 4(4).

19. Marwa I. Comorbidity of diabetes and hypertension and available management strategies in Eastern African region. IOSR J Nur Health Sci. 2017;6(6):1.

20. Hurst C, Thinkhamrop B. The association between hypertension comorbidity and microvascular complications in type 2 diabetes patients: a nationwide cross-sectional study in Thailand. Diabetes Metab J. 2015;39(5):395-404. doi:10.4093/dmj.2015.39.5.395

21. WHO/ISH. 2003 World Health Organization (WHO)/International Society of Hypertension (ISH) statement on management of hypertension. Hypertens (Internet). 2003. Available from: https://journals.lww. com/jhypertension/fulltext/2003/11000/2003_world_health_organiza tion_who_international.2.aspx?casa_token=WzIrXPF6ePsAAAAA: ClyeUJRk9mKfDJFTe6XiZoz21AnOwm1QboFzDIrsS1GwqkbedhPy a-UrH1AHWMv_g10DR00J4bOj1Qwzh2nFqvk. Accessed December 28,2020 .

22. Sakurai M, Nakamura K, Miura K, et al. Family history of diabetes, lifestyle factors, and the 7-year incident risk of type 2 diabetes mellitus in middle-aged Japanese men and women. $J$ Diabetes Investig. 2013;4(3):261-268. doi:10.1111/jdi.12033

23. Wondemagegn AT, Bizuayehu HM, Abie DD, Ayalneh GM, Tiruye TY, Tessema MT. Undiagnosed diabetes mellitus and related factors in East Gojjam (NW Ethiopia) in 2016: a community-based study. J Public Health Res. 2017;6:1. doi:10.4081/jphr.2017.834

24. Shao J, Yu L, Shen X, Li D, Wang K. Waist-to-height ratio, an optimal predictor for obesity and metabolic syndrome in Chinese adults. J Nutr Health Aging. 2010;14(9):782-785. doi:10.1007/ s12603-010-0106-x

25. Mwita JC, Magafu MGMD, Omech B, et al. Undiagnosed and diagnosed diabetes mellitus among hospitalised acute heart failure patients in Botswana. SAGE Open Med. 2017;5:2050312117731473. doi:10.1177/2050312117731473

26. Alemseged F, Haileamlak A, Tegegn A, et al. Risk factors for chronic non-communicable diseases at gilgel gibe field research center, southwest ethiopia: population based study. Ethiop J Health Sci. 2012;22 (4):19-28.
27. FMOH. Guidelines on clinical and programmatic management of major non communicable diseases. Ethiopian Federal ministry of Health; 2016. Available from: https://extranet.who.int/ncdecs/Data/ ETH_D1_National\%20NCD\%20Guideline\%20June\%2010,\% 202016\% $\overline{2}$ [0for\%20print.pdf. Accessed Feb 1, 2020.

28. Wekesah FM, Nyanjau L, Kibachio J, et al. Individual and household level factors associated with presence of multiple non- communicable disease risk factors in Kenyan adults. BMC Public Health. 2018;18 (Suppl 3):1220. doi:10.1186/s12889-018-6055-8

29. Gebremariam LW, Chiang C, Yatsuya H, et al. Non-communicable disease risk factor profile among public employees in a regional city in northern Ethiopia. Sci Rep. 2018;8(1). doi:10.1038/s41598-01827519-6

30. Cherif AB, Bennouar S, Bouamra A, et al. Prevalence of diabetes and dyslipidemia in hypertensive patients in the area of Blida (Algeria). Paper presented at: Annales de Cardiologie et d'Angéiologie, 2018. doi:10.1016/j.ancard.2018.04.015

31. Abebe SM, Berhane Y, Worku A, Assefa A. Diabetes mellitus in North West Ethiopia: a community based study. BMC Public Health. 2014;14(1):97. doi:10.1186/1471-2458-14-97

32. Kidney RS, Peacock JM, Smith SA. Peer Reviewed: blood Glucose Screening Rates Among Minnesota Adults With Hypertension, Behavioral Risk Factor Surveillance System, 2011. Prev Chronic Dis. 2014;11. doi:10.5888/pcd11.140204

33. Eliasson BJ. Cigarette smoking and diabetes. Prog Cardiovasc Dis. 2003;45(5):405-413. doi:10.1053/pcad.2003.00103

34. CDC. Smoking and diabetes. Available from: https://www.cdc.gov/ tobacco/data_statistics/sgr/50th-anniversary/pdfs/fs_smoking_dia betes_508.pdf. Accessed January 20, 2020.

35. Sowers JR, Epstein M, Frohlich EDJH. Diabetes, hypertension, and cardiovascular disease: an update. Hypertension. 2001;37 (4):1053-1059. doi:10.1371/journal.pone.0150033

36. Zerga AA, Bezabih AM, Adhanu AK, Tadesse SE. Obesity indices for identifying metabolic syndrome among type two diabetes patients attending their follow-up in Dessie Referral Hospital, North east Ethiopia. Diabetes Metab Syndr Obes. 2020;13:1297. doi:10.2147/ DMSO.S242792

37. Ahmad SI Diabetes: an old disease, a new insight. Springer Science \& Business Media; 2013. Available from: https://www.researchgate. net/profile/A Bascones/publication/235423579 Periodontal Disease_and_Diabetes/1inks/5dac87f1299bf111d4bf56b1/ Periodontal-Disease-and-Diabetes.pdf. Accessed February 2, 2020.

Diabetes, Metabolic Syndrome and Obesity: Targets and Therapy

Dovepress

Publish your work in this journal

Diabetes, Metabolic Syndrome and Obesity: Targets and Therapy is an international, peer-reviewed open-access journal committed to the rapid publication of the latest laboratory and clinical findings in the fields of diabetes, metabolic syndrome and obesity research. Original research, review, case reports, hypothesis formation, expert opinion and commentaries are all considered for publication. The manuscript management system is completely online and includes a very quick and fair peer-review system, which is all easy to use. Visit http://www.dovepress.com/testimonials.php to read real quotes from published authors. 